\title{
A Comparative Study of Intraperitoneal Ropivacaine and Bupivacaine for Postoperative Analgesia in Laparoscopic Cholecystectomy
}

\author{
Shruti Shrey ${ }^{1}$, Amol Singam², Basant Singh Latwal ${ }^{3}$, Pratibha Nagpure ${ }^{4}$, Ayushma ${ }^{5}$ \\ ${ }^{1}$ Department of Anaesthesiology, AVBRH, JNMC, Sawangi, Wardha, Maharashtra, India. ${ }^{2}$ Department of \\ Anaesthesiology, AVBRH, JNMC, Sawangi, Wardha, Maharashtra, India. ${ }^{3}$ Department of Anaesthesiology, AVBRH, \\ JNMC, Sawangi, Wardha, Maharashtra, India. ${ }^{4}$ Department of Anaesthesiology, AVBRH, JNMC, Sawangi, Wardha, \\ Maharashtra, India. ${ }^{5}$ Department of Anaesthesiology, AVBRH, JNMC, Sawangi, Wardha, Maharashtra, India.
}

\section{ABSTRACT}

\section{BACKGROUND}

Every surgical procedure inflicts pain during the procedure which also continues in the post-operative period as post-operative pain. Intraperitoneal instillation of local anaesthetics in laparoscopic cholecystectomy has been used to reduce postoperative pain and to decrease the need for postoperative analgesics. We wanted to compare intraperitoneal instillation of bupivacaine and ropivacaine for postoperative analgesia in patients undergoing laparoscopic cholecystectomy.

\section{METHODS}

After obtaining ethical committee's clearance and informed consent, sixty patients, aged 20-60 years, of either gender, and American Society of Anaesthesiologists physical status I to II scheduled for laparoscopic cholecystectomy were included and categorized into two groups $(n=30)$. Group B patients received $20 \mathrm{~mL}$ of $0.5 \%$ bupivacaine intraperitoneally after cholecystectomy and Group R patients received $20 \mathrm{~mL}$ of $0.75 \%$ ropivacaine intraperitoneally after cholecystectomy. Mean duration of postoperative analgesia and number of doses of rescue analgesic required were observed. Patients were assessed at 0, 2, 4, 8, 12, 18 and 24 hours postoperatively with respect to quality of analgesia (VAS), hemodynamic parameters and side effects.

\section{RESULTS}

Mean Time for first rescue analgesic requirement was $148.04 \pm 53.47$ min in group $B$ and $295.38 \pm 74.15$ in group $R$ and the difference was statistically significant $(\mathrm{p}=0.0001)$. In group $\mathrm{R} 17(56.6 \%)$ patients did not require any rescue analgesic throughout the study period as compared to $8(26.6 \%)$ patients in group B. The difference between the two groups was statistically significant. $(\mathrm{p}=0.019)$. A lower VAS score was observed in group $\mathrm{R}$ as compared to group $\mathrm{B}$, with statistically significant difference at 2,4 and 8 hours respectively. $(p=0.001,0.003$ and 0.032 ).

\section{CONCLUSIONS}

$0.75 \%$ ropivacaine is a better alternative to $0.5 \%$ bupivacaine when given intraperitoneally for management of postoperative pain in patients undergoing laparoscopic cholecystectomy under general anaesthesia as it prolongs the duration of analgesia, provides a better quality of analgesia till 8 hours postoperatively, with lesser demand and requirement of rescue analgesic in the postoperative period, and has lesser side effects.

\section{KEY WORDS}

Laparoscopic Cholecystectomy, Ropivacaine, Bupivacaine
Corresponding Author:

Dr. Amol Singam,

Professor and HOD,

Department of Anaesthesiology,

AVBRH, JNMC, Sawangi,

Wardha-442001, Maharashtra, India.

E-mail:dramolsingam@gmail.com

DOI: $10.14260 /$ jemds/2020/47

Financial or Other Competing Interests: None.

How to Cite This Article:

Shrey S, Singam A, Latwal BS, et al. A comparative study of intraperitoneal ropivacaine and bupivacaine for postoperative analgesia in laparoscopic cholecystectomy. J. Evolution Med. Dent. Sci. 2020;9(04):200-205, DOI: $10.14260 /$ jemds/2020/47

Submission 25-11-2019,

Peer Review 04-01-2020,

Acceptance 10-01-2020,

Published 27-01-2020. 


\section{BACKGROUND}

Postoperative pain is defined as a condition of tissue injury together with muscle spasm after surgery. ${ }^{1}$ Various studies have shown that post-operative pain is maximum during initial 48-72 hours and it declines thereafter. ${ }^{2,3}$ Laparoscopic cholecystectomy is the preferred surgical technique for uncomplicated cholecystectomy. ${ }^{4}$ Patients often complain of considerable pain in the first 24 hours which peaks within first 4-6 hours. After laparoscopic surgery, visceral pain is experienced due to stretching of intraperitoneal cavity, parietal pain is due to port site incision, peritoneal inflammation and phrenic nerve irritation which manifests as shoulder tip pain. ${ }^{5}$ According to previous studies visceral pain can theoretically be blocked by intraperitoneal instillation, and parietal pain can be blocked by port site infiltration of local anaesthetics. ${ }^{6}$ Numerous local anaesthetics in various concentrations have been used in practice including lignocaine, bupivacaine the latest being Ropivacaine. Bupivacaine is a long acting local anaesthetic routinely used. One of the major adverse effect associated with bupivacaine is its cardiotoxic potential. Ropivacaine has shown to be less toxic to cardiac and central nervous system as compared to Bupivacaine. ${ }^{7}$

This study was intended to know the analgesic efficacy and safety of intraperitoneal ropivacaine and compare it with intraperitoneal bupivacaine for postoperative pain relief in patients undergoing laparoscopic cholecystectomy under general anaesthesia.

\section{METHODS}

This was a randomized control study conducted in the Department of Anaesthesiology, "Acharya Vinoba Bhave Rural Hospital" affiliated to Jawaharlal Nehru Medical College, Sawangi between August 2017 to August 2019. After obtaining prior permission from the Institutional Ethics Committee and written informed consent from all the patients, this study was conducted on patients, age 20-60 years, weighing 40-80 Kg., belonging to ASA class I and II undergoing elective laparoscopic cholecystectomy under general anaesthesia.

Sample size calculation was performed using openepi.com. Assuming mean duration of postoperative analgesia of $165 \pm 30.8 \mathrm{~min}^{8}$ keeping power at $80 \%$ and confidence intervals at 95\% (alpha error at 0.05), a sample of 2 patients would be required to detect a minimum of $15 \%$ difference in the duration of analgesia between the two groups. We included 30 patients in each group to compensate for possible dropouts. The selected patients were randomly allocated into two groups of 30 each based on a computergenerated random number table. Group B (Bupivacaine) patients were given $20 \mathrm{ml}$ of inj. 0.5\% Bupivacaine intraperitoneally. Group R (Ropivacaine) patients were given $20 \mathrm{ml}$ of inj. $0.75 \%$ Ropivacaine intraperitoneally.

One day prior to surgery pre-anaesthetic check-up was done of all the patients. After taking the detailed history thorough general and systemic examination was done to rule out cardiovascular, respiratory, neurological and any associated problems. All routine investigations were done and recorded. Local anaesthetic sensitivity testing was performed on all patients one night prior to surgery. All the patients were counselled regarding general anaesthesia as well as the operative procedure. The Visual Analogue Scale (VAS) was explained to the patients during the preanaesthetic visit. All the patients were kept nil per oral as per the fasting guidelines.

On arrival in the operation theatre, standard ASA monitors were connected to the patients. Patients were administered inj. Glycopyrrolate $4 \mu \mathrm{g} / \mathrm{Kg}$. I.V., inj. midazolam $0.05 \mathrm{mg} / \mathrm{Kg}$. I.V. to allay anxiety and inj. fentanyl $2 \mathrm{mcg} / \mathrm{Kg}$. I.V. as analgesic. Following pre-oxygenation with 100\% oxygen for 3 minutes, patients were induced with inj. propofol $2 \mathrm{mg} / \mathrm{Kg}$. I.V. and injection vecuronium bromide 0.1 $\mathrm{mg} / \mathrm{Kg}$. I.V. and intubated with endotracheal tube of appropriate size $(7.0 / 7.5 \mathrm{~mm}$ internal diameter for female patients and 8.0/8.5 mm internal diameter for male patients). Anaesthesia was maintained with $65 \%$ nitrous oxide $\left(\mathrm{N}_{2} \mathrm{O}\right)$ in $33.5 \% \mathrm{O}_{2}$ supplemented with sevoflurane $1.5 \%$ via closed circuit. Injection vecuronium bromide $0.1 \mathrm{mg} / \mathrm{Kg}$. I.V. was given to maintain sufficient muscle relaxation during surgery. Ventilation i.e. tidal volume $(6-8 \mathrm{ml} / \mathrm{Kg}$.) was adjusted to maintain end tidal carbon dioxide between 35 and $40 \mathrm{mmHg}$. No extra dose of analgesic was given intra operatively to any patient in our study.

All surgeries were performed by the same experienced surgeon. Patients were placed in $15-20^{\circ}$ reverse Trendelenburg position during surgery. During laparoscopy, intra-abdominal pressure was maintained at $12 \mathrm{mmHg}$. After removal of the gall bladder the patients received the drug according to the study group to which they belonged. Drug solution was prepared in pre labelled $20 \mathrm{ml}$ syringes by an independent anaesthesiologist who was not involved in postoperative monitoring to avoid bias in the results of the study. The surgeon sprayed the given solution through the trocar over the right subdiaphragmatic area, the gall bladder bed and the hepatoduodenal ligament under direct vision and patients were placed in $20^{\circ}$ Trendelenburg position for the next 5 minutes to facilitate the dispersion of the drug solution. The $\mathrm{CO}_{2}$ was carefully evacuated at the end of surgery by manual compression of the abdomen with open trocars and all the port sites were completely sutured.

Muscle relaxation was reversed with inj. neostigmine 0.05 $\mathrm{mg} / \mathrm{Kg}$. I.V. and inj. glycopyrrolate $0.01 \mathrm{mg} / \mathrm{Kg}$. I.V. Patients were extubated after thorough oropharyngeal suctioning and were then shifted to the post anaesthesia care unit (PACU). The time of extubation was considered as 0 hour and parameters like pulse rate, mean arterial pressure, respiratory rate recorded at this time were considered to be baseline values.

Pain assessment was done by the investigator, who did not know which drug was instilled intraperitoneally after completion of surgery. Pain parameters including visceral, parietal, and shoulder pain were assessed utilizing visual analog scale (VAS) score where 0 was considered as no pain and 10 as intense pain and rescue analgesic was given at VAS $>=4$. Hemodynamic parameters like pulse rate, mean blood pressure and respiratory rate were recorded at $0,2,4$, $8,12,18$ and 24 hours postoperatively which was considered 
to be the end point of the study. Adverse effects such as nausea, vomiting, arrhythmias, hypotension if it all occurred were made note of and managed. Inj. paracetamol $15 \mathrm{mg} / \mathrm{Kg}$. I.V. over 10 minutes was given as rescue analgesic at VAS $>=4$. Inj. ondansetron $4 \mathrm{mg}$ I.V. was given to treat postoperative nausea and vomiting.

The following parameters were recorded and compared between both the groups

1. Duration of postoperative analgesia which was defined as the time interval from the zero hour postoperatively to the requirement of first rescue analgesic at VAS $>=4$.

2. Quality of analgesia by assessment of VAS score at different time intervals till 24 hours postoperatively.

3. Total number of doses of rescue analgesic required at different time intervals till 24 hours postoperatively.

4. Total number of pain free patients i.e. number of patients who did not require rescue analgesic at all during the study period.

5. Also, side effects if any like changes in vital parameters like heart rate, mean arterial pressure and respiratory rate, nausea and vomiting, arrhythmias etc.

\section{Statistical Analysis}

Qualitative data was presented with the help of percentage table, association among the study groups was assessed with the help of Chi-square test. Quantitative data was presented as mean and standard deviation, comparison among the study groups was done with the help of student t-test. Software used in the analysis were SPSS (Statistical Package for the Social Sciences) 20.0 version and $\mathrm{p}<0.05$ was considered statistically significant.

\section{RESULTS}

Demographically both the groups were comparable with respect to age, gender, weight, ASA class and duration of surgery without any statistically significant difference. (Table 1)

\begin{tabular}{|c|c|c|c|}
\hline & Group B & Group R & p Value \\
\hline Age (yrs.) & $41.06 \pm 10.45$ & $38.83 \pm 11.45$ & 0.433 \\
\hline Gender M:F & $16: 14$ & $13: 17$ & 0.442 \\
\hline Weight (Kg.) & $59.06 \pm 6.86$ & $58.20 \pm 7.27$ & 0.639 \\
\hline ASA Class I:II & $20: 10$ & $21: 9$ & 0.781 \\
\hline Duration of Surgery (min) & $88 \pm 8.61$ & $87.5 \pm 9.73$ & 0.833 \\
\hline \multicolumn{3}{|c|}{ Table 1. Demographic Profile and Duration of Surgery } \\
\hline
\end{tabular}

The mean duration of postoperative analgesia i.e. mean time for requirement of first postoperative rescue analgesic in group B was $148.04 \pm 53.47 \mathrm{~min}$ as compared to $295.38 \pm$ $74.15 \mathrm{~min}$ in group $\mathrm{R}$. The mean duration of postoperative analgesia was prolonged in group $\mathrm{R}$ as compared to group $\mathrm{B}$ with a statistically significant difference between both the groups. $(\mathrm{p}<0.0001)$. (Table 2$)$

\begin{tabular}{|c|c|c|c|}
\hline & Group B & Group R & p Value \\
\hline $\begin{array}{c}\text { Mean duration of postoperative } \\
\text { analgesia (min) }\end{array}$ & $148.04 \pm 53.47$ & $295.38 \pm 74.15$ & $<0.0001$ \\
\hline \multicolumn{3}{|c|}{ Table 2. Mean Duration of Postoperative Analgesia } \\
\hline
\end{tabular}

There was a greater number of pain free patients in Group R as compared to Group B and the difference between the two groups was statistically significant. $(p=0.019)$. The total number of patients demanding for second dose of rescue analgesic in group B were more as compared to group $\mathrm{R}$ with the difference being statistically significant. $(p=0.025)$. (Table 3)

\begin{tabular}{|c|c|c|c|}
\hline $\begin{array}{c}\text { Number of Dose of } \\
\text { Rescue Analgesic }\end{array}$ & Group B n (\%) & Group R n (\%) & p-value \\
\hline 0 & $8(26.6 \%)$ & $17(56.6 \%)$ & 0.019 \\
\hline 1 & $9(30 \%)$ & $8(26.6 \%)$ & 0.771 \\
\hline 2 & $13(43.3 \%)$ & $5(16.6 \%)$ & 0.025 \\
\hline Total & $\mathbf{3 0}(\mathbf{1 0 0} \%)$ & $\mathbf{3 0 ( 1 0 0 \% )}$ & \\
\hline Table 3. Distribution of Patients According to Number of Doses of \\
Rescue Analgesics Required in Both the Groups \\
\hline
\end{tabular}

The mean VAS score in the immediate post-operative period i.e. 0 hour in Group B was $1.30 \pm 0.70$ and that in Group R was $1.13 \pm 0.77$. It was found that the pain intensity score increased with increase in duration. The patients belonging to Group R had comparatively lower VAS score as compared to Group B throughout the study period with the difference being statistically significant at 2-, 4- and 8-hour respectively, ( $p=0.001,0.003,0.032$ ) (graph 1 )

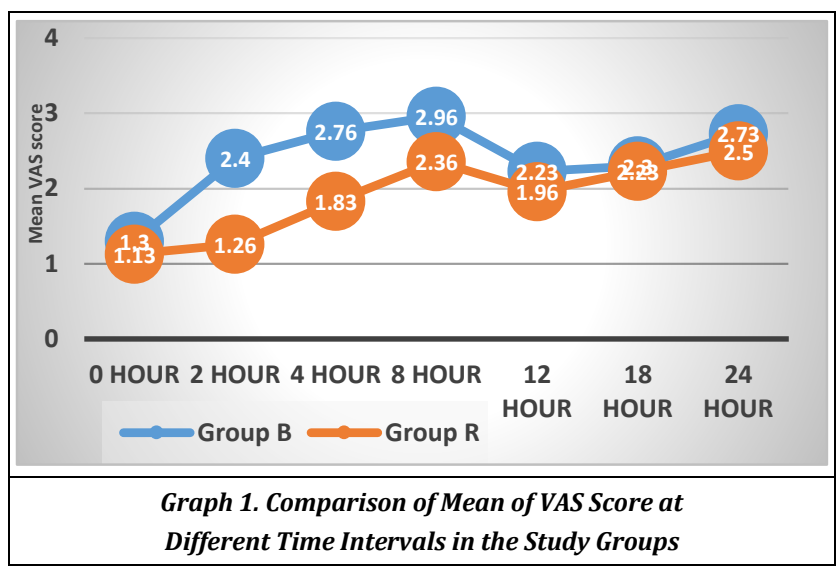

It was observed that there was no rise in the heart rate and mean arterial pressure in the immediate postoperative period. The mean heart rate was lower in Group $\mathrm{R}$ as compared to Group B during first 24 hours, although the difference between the two was statistically non-significant. Patients in both the groups were comparable on the basis of heart rate, mean arterial pressure and respiratory rate with the difference being statistically non-significant. The number of side effects were more in patients belonging to Group B as compared to Group R but without any statistically significant difference. $(p=0.519)$ (Table 4)

\begin{tabular}{|c|c|c|c|}
\hline Side Effects & Group B n (\%) & Group R n (\%) & p Value \\
\hline Nausea & $4(13.33 \%)$ & $4(13.3 \%)$ & \multirow{4}{*}{ 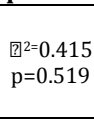 } \\
\hline Vomiting & $2(6.67 \%)$ & $1(3.3 \%)$ & \\
\hline Arrhythmias & $1(3.3 \%)$ & $0(0.00 \%)$ & \\
\hline Total & $7(23.3 \%)$ & $5(16.6 \%)$ & \\
\hline \multicolumn{4}{|c|}{ Table 4. Distribution of Side Effects in Both the Groups } \\
\hline
\end{tabular}

\section{DISCUSSION}

Effective relief of pain is of the utmost importance to anyone treating patients undergoing surgery. Laparoscopic cholecystectomy is an ideal surgery to be performed as a daycare procedure and therefore, the provision of adequate 
postoperative pain relief is of considerable importance. In our study, we chose to provide postoperative analgesia in patients undergoing laparoscopic cholecystectomy via intraperitoneal route. The reason for choosing the intraperitoneal route of local anaesthetic administration is to block the visceral afferent signalling which lead to potential modifications in the visceral nociception thereby providing analgesia. Local anaesthetics that have a longer duration of action and safe pharmacological profile are needed. In our study we have tried to compare $0.5 \%$ bupivacaine with $0.75 \%$ ropivacaine. Various studies have found out that $0.5 \%$ bupivacaine is equipotent to $0.75 \%$ ropivacaine when used for intrathecal, epidural, peripheral nerve block administration.9,10 The potency of ropivacaine versus bupivacaine has been found out to be in a ratio of $3: 2$ according to previous studies.9,11 Mansour et al,12 found bupivacaine $0.5 \%$ and ropivacaine $0.75 \%$ to be equipotent in their study. Similar concentration of the drugs were used by Goldstein et al,13 Porika et al.14

Both the groups were comparable with respect to demographic characteristics like age, gender, weight and ASA class. The patients were also comparable with respect to duration of surgery. Dahmani et $\mathrm{al}^{15}$ found a direct correlation between duration of surgery and increase postoperative pain followed by increased consumption of postoperative opioids, therefore in our study we included patients who underwent surgery within 60-120 min.

The mean duration of postoperative analgesia i.e. mean time for requirement of first postoperative rescue analgesic in group B was $148.04 \pm 53.47 \mathrm{~min}$ as compared to $295.38 \pm$ $74.15 \mathrm{~min}$ in group $\mathrm{R}(\mathrm{p}<0.0001)$. The results thereby obtained indicate that ropivacaine provided a longer duration of postoperative analgesia as compared to bupivacaine, thus illustrating better efficacy of $0.75 \%$ ropivacaine for postoperative analgesia in patients undergoing laparoscopic cholecystectomy as compared to $0.5 \%$ bupivacaine. IPLA is likely to act via blockade of free afferent nerve endings in the peritoneum. Local anaesthetics are also known to have anti-inflammatory actions. ${ }^{16}$ Thus they provide antinociception by affecting nerve membrane associated proteins and by inhibiting the release and action of prostaglandins which stimulate the nociceptors and cause inflammation. ${ }^{8}$ Systemic absorption of local anaesthetic from the peritoneal cavity may also play a part in reducing nociception although this would be expected to occur after any local anaesthetic technique. Systemic levels of local anaesthetic are detectable in the serum circulation as soon as 2 min after bolus instillation into the peritoneum ${ }^{17}$ and a systematic review has recently confirmed that low-dose intraperitoneal local anaesthetic infusion is advantageous when compared to parenteral opioids in patients having abdominal operations. ${ }^{18}$

None of the patients in our study complained of shoulder pain in both the groups and this can be attributed to the intraperitoneal instillation of local anaesthetic into the subdiaphragmatic area and also confirmation of proper evacuation of $\mathrm{CO}_{2}$ pneumoperitoneum by palpation after completion of surgery. Similar observations were made by Bhardwaj et $\mathrm{al}^{19}$ in their study. Pati ${ }^{8}$ in a similar study found out that the mean duration of postoperative analgesia with intraperitoneal bupivacaine was found to be $165.5 \pm 30.8$ min. Vellingiri et $\mathrm{al}^{20}$ in their study found that mean duration of postoperative analgesia with intraperitoneal ropivacaine was $264.33 \pm 144.79$ min which was in accordance with the results of our study. Ropivacaine when given intraperitoneally starts acting within 10-20 min, and duration of action lasts for 4-6 h. ${ }^{21}$ In a study conducted by Porika et al ${ }^{14}$ mean time taken for administration of rescue analgesia was $8.23 \pm 0.5$ hours in patients receiving intraperitoneal ropivacaine which was significantly more as compared to $7.6 \pm 0.52$ hours in patients receiving intraperitoneal bupivacaine. In a recent study conducted by Sharan et $\mathrm{al}^{22}$ similar results were obtained where the mean time for requirement of first rescue analgesic was $150.00 \pm$ 86.40 min with bupivacaine as compared to $162.22 \pm 124.16$ min with ropivacaine but the difference between the two groups was statistically non-significant.

Patients who did not require any rescue analgesic throughout the study period were labelled as pain free. We observed that in group $\mathrm{R}$ a greater number of patients did not require any rescue analgesic throughout the study period as compared to patients in group B with the difference being statistically significant. With respect to the second dose of rescue analgesic required, we observed that in group R only 5 (16.6\%) patients required second dose of rescue analgesic as compared to $13(43.3 \%)$ in group B. Similar results were obtained in studies conducted by Albuquerque et al,23 Porika et al. ${ }^{14}$ The findings of our study were also supported by a study conducted by Sharan et $\mathrm{al}^{22}$ in which similar results were obtained with lesser number of patients requiring rescue analgesic with ropivacaine as compared to bupivacaine. VAS score was used to assess the quality of analgesia. The mean VAS score in the immediate postoperative period i.e. 0 hour in group B was $1.30 \pm 0.70$ and that in group $\mathrm{R}$ was $1.13 \pm 0.77$. It was found that the pain intensity score increased with increase in duration. The patients belonging to group $\mathrm{R}$ had significantly lower VAS score at various time intervals as compared to group B with statistically significant difference at 2, 4 and 8 hours respectively. ( $p=0.001,0.003$ and 0.032 ) Thus we can say that better quality of analgesia was provided by ropivacaine till 8 hours postoperatively as compared to bupivacaine. In a study conducted by Sharan et al $^{22}$ similar results were obtained where lower VAS score was observed at 4,6,8 hour in patients who received intraperitoneal ropivacaine as compared to those who received bupivacaine. In similar studies conducted by Chundrigar et $\mathrm{al}^{24}$ Mraovic et al 25 postoperative VAS score was found to be lower in the first 8 hours in the study group which is in accordance with the results of our study.

Patients were shifted to the PACU and were monitored at defined time intervals. The mean heart rate was lower in Group R as compared to Group B during first 24 hours, although the difference between the two was statistically non-significant. Patients in both the groups were comparable on the basis of hemodynamic parameters. Similar results were obtained by Kucuk et $\mathrm{al}^{26}$ and Porika et $\mathrm{al}^{14}$ where no significant change in heart rate, mean arterial pressure and respiratory rate was noted amongst the study groups.

Both the groups witnessed similar incidences of nausea vomiting. This can be explained by the fact that the incidence of PONV after laparoscopic cholecystectomy is higher than that after other types of surgery ${ }^{27}$ and cannot be attributed to the study drugs. In our study, one patient developed 
arrhythmia in the bupivacaine group whereas in the ropivacaine group no such side effects were seen. Arrhythmias after instillation of bupivacaine could be due to inadvertent intravascular injection or absorption of the drug. Similar observations were noted in a study conducted by Sharan et $\mathrm{al}^{22}$ where one patient developed arrhythmia after intraperitoneal instillation of bupivacaine. Overall patients belonging to bupivacaine group developed more side effects as compared to ropivacaine.

\section{CONCLUSIONS}

Intraperitoneal instillation of $20 \mathrm{ml} 0.75 \%$ ropivacaine is a better alternative to intraperitoneal $20 \mathrm{ml} 0.5 \%$ bupivacaine for the management of postoperative pain in patients undergoing laparoscopic cholecystectomy under general anaesthesia as it prolongs the duration of analgesia, provides a better quality of analgesia till 8 hours postoperatively, with lesser demand and requirement of rescue analgesic in the postoperative period, and has lesser side effects.

\section{Limitations}

We did not consider the fact that preoperative use of opioids might have interfered with our study drugs in the postoperative management of pain. Also, we did not compare intraperitoneal local anaesthetics with other modalities of postoperative pain management like IV NSAIDs, opioids and nerve blocks. We did not measure the plasma concentrations of our study drugs to ensure that the levels of both the drugs were well below the toxic concentrations.

\section{REFERENCES}

[1] Healy T, Knight P. Wylie Churchill-Davidson's A practice of anesthesia. $7^{\text {th }}$ edn. London: CRC Press 2003.

[2] Simpson BRJ, Parkhouse J. The problem of postoperative pain. British Journal of Anaesthesia 1961;33 (7):336-44.

[3] Large RG, Schug SA. Opioids for chronic pain of nonmalignant origin--caring or crippling. Health Care Anal 1995;3 (1):5-11.

[4] Saunders CJ, Leary BF, Wolfe BM. Is outpatient laparoscopic cholecystectomy wise? Surg Endosc 1995;9 (12):1263-8.

[5] Gupta A, Thörn SE, Axelsson K, et al. Postoperative pain relief using intermittent injections of $0.5 \%$ ropivacaine through a catheter after laparoscopic cholecystectomy. Anesth Analg 2002;95 (2):450-6.

[6] Thomas DF, Lambert WG, Williams KL. The direct perfusion of surgical wounds with local anaesthetic solution: an approach to postoperative pain? Ann R Coll Surg Engl 1983;65 (4):226-9.

[7] Moller R, Covino BG. Cardiac electrophysiologic properties of bupivacaine and lidocaine compared with those of ropivacaine, a new amide local anesthetic. Anesthesiology 1990;72 (2):322-9.
[8] Pati BK. Intraperitoneal analgesia for postoperative pain relief after laparoscopic gynecological surgeries. Int J Reprod Contracept Obstet Gynecol 2017;6 (11):5099102.

[9] Cannata F, Amicone M, Canneti A, et al. Spinal anaesthesia for transurethral prostate resection: Isobaric ropivacaine $0.75 \%$ versus isobaric bupivacaine 0.5\%: 8AP3-3. Eur J Anaesthesiol (EJA) 2008;25:112.

[10] Chandran S, Hemalatha S, Viswanathan P. Comparison of $0.75 \%$ ropivacaine and $0.5 \%$ bupivacaine for epidural anaesthesia in lower extremity orthopaedic surgeries. Indian J Anaesth 2014;58 (3):336-8.

[11] Malinovsky JM, Charles F, Kick 0 , et al. Intrathecal anesthesia: ropivacaine versus bupivacaine. Anesth Analg 2000;91 (6):1457-60.

[12] Mansour NA, Al-Mahdy F, Abdel-Monem MT. Ropivacaine versus bupivacaine in postoperative pain control. J Biotechnol Biomater 2012;2 (4):1-7.

[13] Goldstein A, Grimault P, Henique A, et al. Preventing postoperative pain by local anesthetic instillation after laparoscopic gynecologic surgery: a placebo-controlled comparison of bupivacaine and ropivacaine. Anesth Analg 2000;91 (2):403-7.

[14] Porika ST, Lakshmi VN. Intraperitoneal nebulization of ropivacaine $0.75 \%$ vs intraperitoneal nebulization of bupivacaine $0.5 \%$ for post-operative analgesia in laparoscopic surgeries: prospective double blinded randomised controlled trial. IAIM 2018;5 (9):105-17.

[15] Dahmani S, Dupont H, Mantz J, et al. Predictive factors of early morphine requirements in the post-anaesthesia care unit (PACU). British Journal of Anaesthesia 2001;87 (3):385-9.

[16] MacGregor RR, Thorner RE, Wright DM. Lidocaine inhibits granulocyte adherence and prevents granulocyte delivery to inflammatory sites. Blood 1980;56 (2):203-9.

[17] Fuhrer Y, Charpentier C, Boulanger G, et al. Analgesia after laparoscopic cholecystectomy by intraperitoneal administration of bupivacaine. Ann Fr Anesth Reanim 1996;15 (2):128-34.

[18] Marret E, Rolin M, Beaussier M, et al. Meta-analysis of intravenous lidocaine and postoperative recovery after abdominal surgery. Br J Surg 2008;95 (11):1331-8.

[19] Bhardwaj N, Sharma V, Chari P. Intraperitoneal bupivacaine instillation for post-operative pain relief after laparoscopic cholecystectomy. Indian J Anaesth 2002;46 (1):49-52.

[20] Vellingiri M, Bhavani M. Study on the comparison of intraperitoneal instillation of bupivacaine, ropivacaine and saline for post-operative pain relief after laparoscopic intra-abdominal surgeries. International Journal of Advanced Research 2018;6 (4):1376-9.

[21] Lee A, Fagan D, Lamont M, et al. Disposition kinetics of ropivacaine in humans. Anesth Analg 1989;69 (6):736-8.

[22] Sharan R, Singh M, Kataria AP, et al. Intraperitoneal instillation of bupivacaine and ropivacaine for postoperative analgesia in laparoscopic cholecystectomy. Anesth Essays Res 2018;12 (2):377-80.

[23] De Albuquerque TL, Bezerra MF, Schots CC, et al. Evaluation of postoperative analgesia with intraperitoneal ropivacaine instillation in videolaparoscopic cholecystectomy. Rev Dor, Sao Paulo 2016;17 (2):117-20. 
[24] Chundrigar T, Hedges AR, Morris R, et al. Intraperitoneal bupivacaine for effective pain relief after laparoscopic cholecystectomy. Ann R Coll Surg Engl 1993;75 (6):4379.

[25] MraoviČ B, JurišiČ $\quad T$, Kogler-Majeric $\mathrm{V}$, et al. Intraperitoneal bupivacaine for analgesia after laparoscopic cholecystectomy. Acta Anaesthesiol Scand 1997;41 (2):193-6.

[26] Kucuk C, Kadiogullari N, Canoler O, et al. A placebocontrolled comparison of bupivacaine and ropivacaine instillation for preventing postoperative pain after laparoscopic cholecystectomy. Surg Today 2007;37 (5):396-400.

[27] Naguib M, el Bakry AK, Khoshim MH, et al. Prophylactic antiemetic therapy with ondansetron, tropisetron, granisetron and metoclopramide in patients undergoing laparoscopic cholecystectomy: a randomized, doubleblind comparison with placebo. Can J Anaesth 1996;43 (3):226-31. 